\title{
Elevation of Serum Acid Sphingomyelinase Activity in Acute Kawasaki Disease
}

\author{
Yuuki Konno, ${ }^{1}$ Ikuko Takahashi, ${ }^{1}$ Ayuko Narita, ${ }^{2}$ Osamu Takeda, ${ }^{3}$ \\ Hiromi Koizumi, ${ }^{3}$ Masamichi Tamura, ${ }^{4}$ Wataru Kikuchi, ${ }^{5}$ Akira Komatsu, ${ }^{6}$ \\ Hiroaki Tamura, ${ }^{1}$ Satoko Tsuchida, ${ }^{1}$ Atsuko Noguchi ${ }^{1}$ and Tsutomu Takahashi ${ }^{1}$
}

\author{
${ }^{1}$ Department of Pediatrics, Akita University Graduate School of Medicine, Akita, Akita, Japan \\ ${ }^{2}$ Division of Pediatrics, Yamamoto General Hospital, Noshiro, Akita, Japan \\ ${ }^{3}$ Division of Pediatrics, Akita Municipal General Hospital, Akita, Akita, Japan \\ ${ }^{4}$ Division of Pediatrics, Akita Red-Cross Hospital, Akita, Akita, Japan \\ ${ }^{5}$ Division of Pediatrics, Ogachi Central Hospital, Yuzawa, Akita, Japan \\ ${ }^{6}$ Division of Pediatrics, Yokote Municipal Hospital, Yokote, Akita, Japan
}

\begin{abstract}
Kawasaki disease (KD) is an acute systemic vasculitis that affects both small and medium-sized vessels including the coronary arteries in infants and children. Acid sphingomyelinase (ASM) is a lysosomal glycoprotein that hydrolyzes sphingomyelin to ceramide, a lipid, that functions as a second messenger in the regulation of cell functions. ASM activation has been implicated in numerous cellular stress responses and is associated with cellular ASM secretion, either through alternative trafficking of the ASM precursor protein or by means of an unidentified mechanism. Elevation of serum ASM activity has been described in several human diseases, suggesting that patients with diseases involving vascular endothelial cells may exhibit a preferential elevation of serum ASM activity. As acute KD is characterized by systemic vasculitis that could affect vascular endothelial cells, the elevation of serum ASM activity should be considered in these patients. In the present study, serum ASM activity in the sera of 15 patients with acute KD was determined both before and after treatment with infusion of high-dose intravenous immunoglobulin (IVIG), a first-line treatment for acute KD. Serum ASM activity before IVIG was significantly elevated in KD patients when compared to the control group $(3.85 \pm 1.46 \mathrm{nmol} / 0.1 \mathrm{ml} / 6 \mathrm{~h}$ vs. $1.15 \pm 0.10 \mathrm{nmol} / 0.1 \mathrm{ml} / 6 \mathrm{~h}, \mathrm{p}<$ 0.001 ), suggesting that ASM activation may be involved in the pathophysiology of this condition. Serum ASM activity before IVIG was significantly correlated with levels of C-reactive protein $(p<0.05)$. These results suggest the involvement of sphingolipid metabolism in the pathophysiology of KD.
\end{abstract}

Keywords: acid sphingomyelinase; ceramide; C-reactive protein; Kawasaki disease; sphingolipid metabolism Tohoku J. Exp. Med., 2015 October, 237 (2), 133-140. C 2015 Tohoku University Medical Press

\section{Introduction}

Kawasaki disease $(\mathrm{KD})$ is an acute systemic vasculitis of unknown etiology that predominantly affects infants and children younger than 5 years of age (Newburger et al. 2004). Clinical manifestations of KD include prolonged fever, conjunctival injection, oral lesions, polymorphous skin rashes, extremity changes, and cervical lymphadenopathy, all of which comprise the condition's diagnostic criteria (Ayusawa et al. 2005). Vasculitis in KD affects both small and medium-sized arteries and includes the coronaries arteries - indeed, the development of coronary artery lesions (CALs) such as aneurysms and ectasias is a major complication, determining the prognosis of this disease (Newburger et al. 2004). High-dose intravenous immunoglobulin (IVIG) therapy is a standard treatment for KD and reduces the incidence of CALs (Furusho et al. 1984; Newburger et al. 1986, 1991).

Approximately $10 \%$ of patients fail to respond to IVIG, and higher CAL incidence rates are observed in these cases (Burns et al. 1998; Han et al. 2000; Tremoulet et al. 2008; Uehara et al. 2008). While the etiology of KD remains unknown, numerous studies have shown that serum levels of various inflammatory cytokines, such as interleukin-6 (IL-6) and tumor necrosis factor- $\alpha$ (TNF- $\alpha$ ), are elevated in acute cases (Suzuki et al. 2001; Jang et al. 2003; Hui-Yuen et al. 2006; Wu et al. 2011; Sato et al. 2013; Wang et al. 2013; Weng et al. 2013). Some studies have reported elevated serum IL-6 levels in patients with acute $\mathrm{KD}$ and a correlation between these serum levels and responsiveness to high-dose IVIG treatment has further been observed (Sato et al. 2013; Wang et al. 2013).

Received April 23, 2015; revised and accepted September 4, 2015. Published online October 7, 2015; doi: 10.1620/tjem.237.133.

Correspondence: Tsutomu Takahashi, M.D., Department of Pediatrics, Akita University Graduate School of Medicine, 1-1-1 Hondo, Akita, Akita 010-8543, Japan.

e-mail: tomy@med.akita-u.ac.jp 
Acid sphingomyelinase (ASM) is a lysosomal glycoprotein that catalyzes the hydrolysis of the lipid sphingomyelin (a major component of the cellular membrane) to ceramide and phosphocholine (Schuchman 2010). Ceramide is a bioactive lipid that functions as a second messenger in the regulation of cell proliferation, survival, and death (Zeidan and Hannun 2010). Inherited ASM deficiency thus results in Niemann-Pick disease types A and B, lysosomal storage disorders characterized by the accumulation of sphingomyelin in various cells and tissues (Schuchman 2010).

The sphingomyelin phosphodiesterase 1 (SMPD1) gene, which encodes lysosomal ASM, has also been attributed to another form of ASM via differential protein trafficking of a common precursor, secretory ASM (S-ASM) (Schissel et al. 1996). Lysosomal ASM binds zinc $\left(\mathrm{Zn}^{2+}\right)$ ions during trafficking to lysosomes and is therefore independent of exogenous $\mathrm{Zn}^{2+}$, while S-ASM is dependent on the exogenous addition of $\mathrm{Zn}^{2+}$ for enzyme assay (Schissel et al. 1998). ASM activation has been implicated in many cellular stress responses, including cell death and inflammatory signaling, and is in fact associated with cellular ASM secretion, either through alternative trafficking of the ASM precursor protein or by means of an unidentified mechanism (Jenkins et al. 2010). In experimental mouse models, elevated levels of S-ASM in response to the administration of lipopolysaccharide or pro-inflammatory cytokines (such as interleukin- $1 \beta$ or TNF- $\alpha$ ) have been described (Wong et al. 2000). In addition, recent studies have shown that serum S-ASM is increased in several human diseases including systemic inflammation, sepsis, hemophagocytic lymphohistiocytosis, type 2 diabetes mellitus, chronic heart failure, alcohol-dependency, chronic hepatitis $\mathrm{C}$ infection, and nonalcoholic fatty liver (Takahashi et al. 2002; Górska et al. 2003; Claus et al. 2005; Doehner et al. 2007; Reichel et al. 2011; Jenkins et al. 2013; Grammatikos et al. 2014).

Reports on the relationship between S-ASM and human diseases suggest that diseases with endothelial involvement appear to preferentially present a marked elevation of peripheral S-ASM activity (Kornhuber et al. 2015). An in vitro study also showed that human vascular endothelial cells are a rich source of S-ASM (Marathe et al. 1998). As acute KD is characterized by systemic vasculitis that could affect the vascular endothelial cells, S-ASM should be evaluated in these patients.

The aim of the present study was to evaluate the serum levels of S-ASM in patients with acute KD during treatment with IVIG, as well as to investigate the clinical significance of S-ASM activity in acute KD patients.

\section{Methods}

\section{Patient sampling}

Fifteen children in the acute phase of $\mathrm{KD}$ were enrolled in this study: 10 boys and 5 girls between 4 months and 4 years of age. Demographic patient characteristics are summarized and presented in Table 1. Patients were diagnosed in accordance with the Diagnostic Guidelines for Kawasaki Disease and were admitted to our hospitals between November 2012 and May 2014 (Ayusawa et al. 2005). All patients were initially treated with oral aspirin or flurbiprofen followed by administration of $2 \mathrm{~g} / \mathrm{kg}$ IVIG infusion. Three patients required more than double the initial IVIG infusion dose $(4-6 \mathrm{~g} / \mathrm{kg}$ in total) for resolution of fever. Blood samples were collected prior to treatment and upon admission as well as 24 to $48 \mathrm{~h}$ after the final IVIG treatment. ASM serum levels were determined in 5 healthy children (6 to 8 years of age) and 4 healthy adults (39 to 42 years of age) as a control for this study. S-ASM levels were also determined in 4 children with an adenovirus infection (1.3 to 4 years of age; C-reactive protein [CRP], $2.0 \pm 2.8 \mathrm{mg} / \mathrm{L}$ ) included as disease controls. These 4 children presented with fever and upper respiratory symptoms and were diagnosed with adenovirus infection by using rapid antigen detection kit.

Medical records were reviewed for age, sex, clinical symptoms, complications, responsiveness to IVIG therapy, and laboratory data including white blood cell (WBC) count, platelet count, and levels of hemoglobin, alanine aminotransferase, aspartate aminotransferase,

Table 1. Demographic characteristics of $15 \mathrm{KD}$ patients.

\begin{tabular}{lcc}
\hline Age (months) & $28.9 \pm 16.0$ & $(7-57)$ \\
Sex & & \\
Male & $10(66.7 \%)$ & \\
Female & $5(33.3 \%)$ & \\
Coronary artery change (Echocardiography) & & \\
$\quad$ Yes & $1(6.7 \%)$ & \\
$\quad$ No & $14(93.3 \%)$ & $(6,500-28,400)$ \\
White blood cells $(/ \mu \mathrm{L})$ & $14,493.3 \pm 5,406.4$ & $(28.7-40.5)$ \\
Neutrophil $(\%)$ & $69.7 \pm 17.7$ & $(13.8-54.8)$ \\
Hematocrit $(\%)$ & $33.7 \pm 3.7$ & $(1.74-24.8)$ \\
Platelet $\left(\times 10^{4} / \mu \mathrm{L}\right)$ & $30.2 \pm 13.4$ & $(128-438)$ \\
C-reactive protein $(\mathrm{mg} / \mathrm{L})$ & $7.9 \pm 6.0$ & \\
AST $(\mathrm{IU} / \mathrm{L})$ & $81.5 \pm 130.6$ & \\
Na $(\mathrm{mEq} / \mathrm{L})$ & $134.4 \pm 3.5$ & \\
\hline
\end{tabular}

AST, aspartate aminotransferase; Na, serum sodium. 
lipids, electrolytes, and CRP. Coronary artery evaluation was performed using two-dimensional echocardiography (Research Committee on Kawasaki Disease 1984).

Ethical approval was obtained from the Ethics Committee of Akita University, Graduate School of Medicine in Akita, Japan. Written informed consent was obtained from the parents of the patients enrolled.

\section{Measurements of serum ASM and IL-6}

S-ASM levels were measured using an assay buffer with $\mathrm{Zn}^{2+}$ as $\mathrm{Zn}^{2+}$-dependent S-ASM. $\mathrm{Zn}^{2+}$-independent ASM was concurrently measured using an assay buffer with ethylenediaminetetraacetic acid (EDTA) because the activation of ASM can be confirmed when $\mathrm{Zn}^{2+}$ dependent S-ASM activity is higher than $\mathrm{Zn}^{2+}$-independent ASM activity. Assays for $\mathrm{Zn}^{2+}$-independent $\mathrm{ASM}$ and $\mathrm{Zn}^{2+}$-dependent S-ASM activity were performed using ${ }^{14} \mathrm{C}$-labeled sphingomyelin (PerkinElmer, MA, USA) (Goñi and Alonso 2002). A standard 200 $\mu \mathrm{L}$ assay mixture consisting of $100 \mu \mathrm{L}$ serum and $50 \mu \mathrm{L}$ assay buffer with $4 \%$ Triton X-100 (1.0 M sodium acetate, $\mathrm{pH} 5.0$ ) was used (final concentration of Triton X-100, 1\%). Final concentrations of EDTA and $\mathrm{Zn}^{2+}$ in the assay buffer were $0.02 \mathrm{mM}$ and $0.1 \mathrm{mM}$, respectively. For investigating the effect of buffer $\mathrm{pH}$ on the sphingomyelin hydrolysis by serum, assays were performed using $0.1 \mathrm{M}$ glycine $\mathrm{HCl}-$ buffer ( $\mathrm{pH}$ 3.0), 0.1 M acetate buffer ( $\mathrm{pH} 4.0$ and $\mathrm{pH} 5.0$ ), and $0.1 \mathrm{M}$ phosphate buffer (pH 6.0 and $\mathrm{pH}$ 7.0) with either EDTA or $\mathrm{Zn}^{2+}$.

The reaction was initiated by addition of $50 \mu \mathrm{L}$ of substrate $(20$ nmol, ${ }^{14} \mathrm{C}$-labeled sphingomyelin, and $0.08 \mu \mathrm{Ci} / 20 \mathrm{nmol}$ ) in $0.2 \%$ taurodeoxycholic acid. Assay mixtures were incubated at $37^{\circ} \mathrm{C}$ for 6 h. The assay was terminated with $200 \mu \mathrm{L}$ ice-cold $30 \%$ trichloroacetate and $400 \mu \mathrm{L} 2.5 \%$ bovine serum albumin. Tubes were briefly vortexed and allowed to settle for $5 \mathrm{~min}$ at room temperature before centrifugation $(5 \mathrm{~min}, 3,000 \mathrm{rpm})$. The supernatant $(500 \mu \mathrm{L})$ was carefully aspirated and transferred into glass scintillation vials. Radioactivity was measured directly after mixing with $4.5 \mathrm{~mL}$ Clearsol II (Nakalai Tesque, Kyoto, Japan) in a liquid scintillation counter LSC 950 (Aloka, Tokyo, Japan).

Serum IL-6 was measured using human IL-6 chemiluminescent enzyme immunoassay (CLEIA) kits (Fujirebio, Tokyo, Japan).

\section{Risk scoring of acute KD using the Kobayashi Score}

The risk scoring method for acute KD was used in this study (Kobayashi et al. 2006). Two points were assigned for each of the following: a serum sodium concentration of $\leq 133 \mathrm{nmol} / \mathrm{L}, \leq 4$ days of illness at diagnosis, an aspartate aminotransferase concentration of $\geq 100 \mathrm{U} / \mathrm{L}$, and WBCs with a neutrophil count of $\geq 80 \%$. One point was assigned for each of the following: platelet count of $\leq 30 \times 10^{4}$ / $\mu \mathrm{L}, \mathrm{CRP}$ concentration of $\geq 100 \mathrm{mg} / \mathrm{L}$, and age $\leq 12$ months. If the risk score is $\geq 5$ points, the positive predictive value of non-response to initial IVIG infusion is emphasized.

\section{Statistical analysis}

Data were analyzed using the IBM SPSS Statistics 22.0 software package and are presented as the mean \pm standard deviation (SD). A Students' unpaired t-test was used to compare the mean differences between 2 groups and a Pearson's correlation coefficient test was used to examine the correlation between ASM serum levels and laboratory data. A p-value $<0.05$ was considered statistically significant.

\section{Results}

ASM in acute KD patients: serum levels and optimal $p H$

To our knowledge, serum ASM activity in KD patients has not been previously investigated. In the present study, serum ASM activity was shown to be significantly elevated in patients with acute $\mathrm{KD}$ (Table 2). In a group of 5 healthy control children (6 to 8 years of age), the serum ASM activity was measured using two assay buffers with either EDTA or $\mathrm{Zn}^{2+}: 0.42 \pm 0.04 \mathrm{nmol} / 0.1 \mathrm{~mL} / 6 \mathrm{~h}$ and $1.15 \pm 0.10$ $\mathrm{nmol} / 0.1 \mathrm{~mL} / 6 \mathrm{~h}$, respectively. In the second group of 4 healthy control adults (39-42 years of age), the serum ASM activity was measured as above and shown to be $0.36 \pm 0.05$ $\mathrm{nmol} / 0.1 \mathrm{~mL} / 6 \mathrm{~h}$ and $0.99 \pm 0.23 \mathrm{nmol} / 0.1 \mathrm{~mL} / 6 \mathrm{~h}$, respectively. In the third group of 4 children with adenovirus infection, the serum ASM activity was measured as $0.68 \pm$ $0.32 \mathrm{nmol} / 0.1 \mathrm{ml} / 6 \mathrm{~h}$ and $1.60 \pm 0.69 \mathrm{nmol} / 0.1 \mathrm{ml} / 6 \mathrm{~h}$, respectively.

In contrast, the serum ASM activity before IVIG treatment measured using the same methodology was $1.28 \pm$ $0.59 \mathrm{nmol} / 0.1 \mathrm{~mL} / 6 \mathrm{~h}$ and $3.85 \pm 1.46 \mathrm{nmol} / 0.1 \mathrm{~mL} / 6 \mathrm{~h}$, respectively (Table 2). The serum ASM activity after IVIG treatment was $1.31 \pm 0.45 \mathrm{nmol} / 0.1 \mathrm{~mL} / 6 \mathrm{~h}$ and $3.84 \pm 1.19$ $\mathrm{nmol} / 0.1 \mathrm{~mL} / 6 \mathrm{~h}$, respectively.

The effects of buffer $\mathrm{pH}$ on the hydrolysis of sphingomyelin by serum were examined in 2 patients. Under assay conditions, ASM activity was optimal at approximately $\mathrm{pH}$ 5 in both EDTA and $\mathrm{Zn}^{2+}$ assay buffers (Fig. 1).

Table 2. ASM activity in acute KD patients and healthy controls.

\begin{tabular}{lcc}
\hline & \multicolumn{2}{c}{ Activity $(\mathrm{nmol} / 0.1 \mathrm{~mL} / 6 \mathrm{~h})$} \\
\cline { 2 - 3 } & $\mathrm{Zn}^{2+}(-) \operatorname{EDTA}(+)$ & $\mathrm{Zn}^{2+}(+) \operatorname{EDTA}(-)$ \\
\hline Normal adult $(\mathrm{n}=4)$ & $0.36 \pm 0.05$ & $0.99 \pm 0.23$ \\
Normal children $(\mathrm{n}=5)$ & $0.42 \pm 0.04$ & $1.15 \pm 0.10$ \\
Children with adenovirus infection $(\mathrm{n}=4)$ & $0.68 \pm 0.32$ & $1.60 \pm 0.69$ \\
Pre-IVIG in acute KD patients & $1.28 \pm 0.59^{*}$ & $3.85 \pm 1.46^{* *}$ \\
Post-IVIG in acute KD patients & $1.31 \pm 0.45^{* *}$ & $3.84 \pm 1.19^{* *}$ \\
\hline
\end{tabular}

$* \mathrm{p}<0.01$ vs. normal children, $* * \mathrm{p}<0.001$ vs. normal children (Unpaired t-test).

ASM, acid sphingomyelinase; IVIG, intravenous immunoglobulin; EDTA, ethylenediaminetetraacetic acid. 


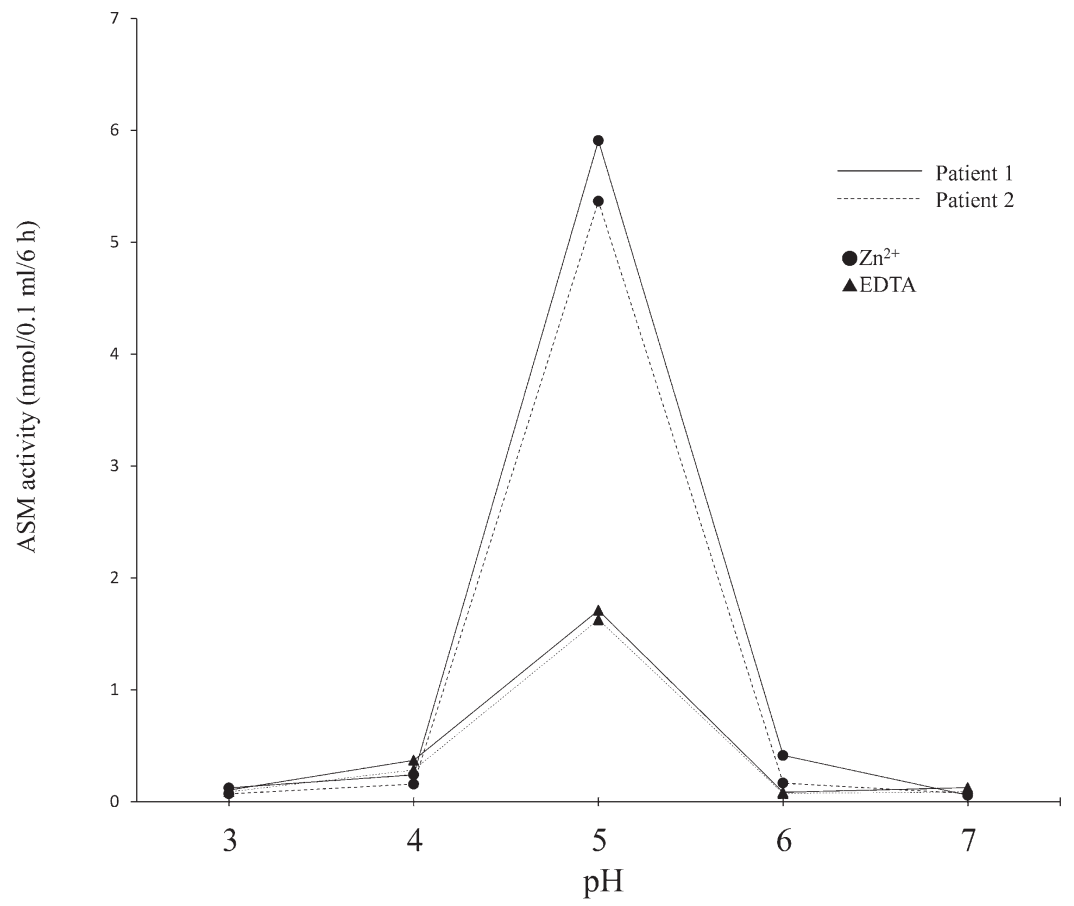

Fig. 1. Optimal $\mathrm{pH}$ for sphingomyelin hydrolysis by sera from patients with acute KD.

Effect of buffer $\mathrm{pH}$ on sphingomyelin hydrolysis by serum samples from two patients with acute KD was examined. Sphingomyelin was incubated with $100 \mu \mathrm{L}$ serum in ethylenediaminetetraacetic acid (EDTA) or $\mathrm{Zn}^{2+}$ buffer.

IL-6 in acute KD patients: serum levels before and after IVIG infusion

In the present study, serum IL-6 levels were significantly elevated before IVIG treatment in all enrolled patients and were normalized to baseline levels after IVIG treatment as described above (Fig. 2). However, serum IL-6 levels were not significantly correlated with the responsiveness of the disease to high-dose IVIG in our small group of acute KD patients. No correlation was observed between ASM activity and serum IL-6 levels.

\section{Serum ASM activity after IVIG infusion}

In the present study, 12 patients were shown to be responsive to an initial high-dose IVIG infusion, while 3 patients were found to be nonresponsive. Serum ASM activity in responsive and nonresponsive patients was not significantly different.

Risk-scoring systems such as the Kobayashi score have been created and evaluated for their clinical efficacy in predicting the nonresponsiveness of acute $\mathrm{KD}$ patients to high-dose IVIG treatment (Kobayashi et al. 2006; Sleeper et al. 2011). The relationship between serum ASM activity and the Kobayashi score (a widely used risk scoring system in Japan) was investigated. In the present study, no correlation of serum ASM activity was observed between groups with a risk score $<5$ and with a risk score $\geq 5$ or higher (indicating high risk for nonresponsiveness to high-dose IVIG) (Fig. 3).
A single acute KD patient with high-dose IVIG resistance: serial measurement of serum ASM

The serum ASM activity was serially determined in a single nonresponsive KD patient suffering from inflammation, from the time of hospital admission up to discharge (Fig. 4). Throughout the clinical course, ASM activity remained elevated until the second high-dose IVIG infusion, after which measurements did appear to gradually decrease toward basal levels. However, while the serum ASM activity was not immediately altered following resolution of inflammation in response to high-dose IVIG infusion, IL-6 levels did reflect an immediate change in the inflammatory state of this acute KD patient.

Correlation analyses of serum ASM levels in acute KD patients

We further examined any correlations between preIVIG serum ASM activity and other clinical and biochemical parameters, including serum sodium concentration, days of illness at diagnosis, aspartate aminotransferase concentration, percentage of neutrophils among WBCs, platelet count, CRP concentration, and ages at onset. Correlation analyses revealed that the serum ASM activity is significantly associated with CRP levels in patients with acute KD (Table 3).

\section{Discussion}

In the present study, we investigated the role of serum ASM activity in acute KD patients. Serum levels of both lysosomal and secretory ASM were significantly elevated in 


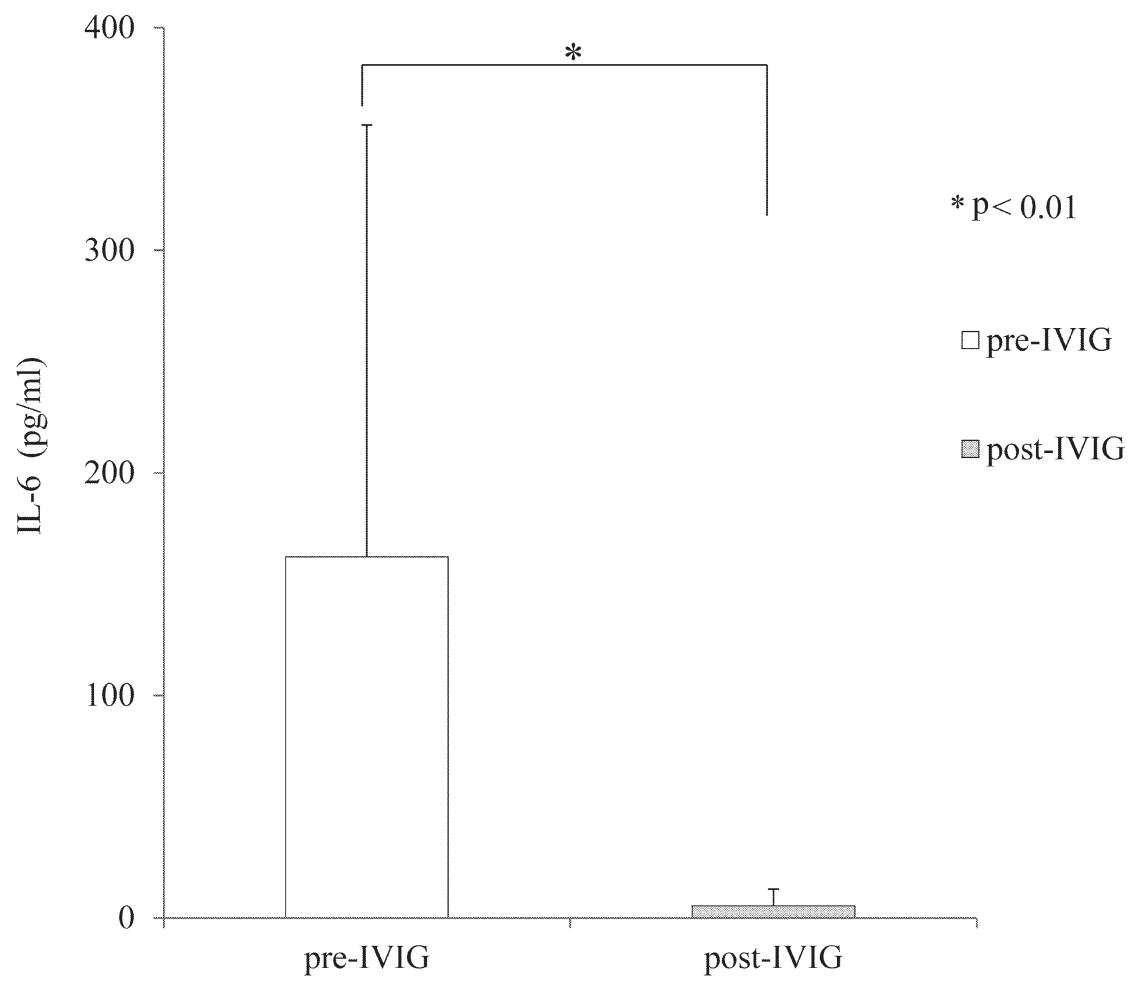

Fig. 2. Serum interleukin-6 levels in patients with acute KD.

Pre- and post-intravenous immunoglobulin (IVIG) serum levels of interleukin-6 (IL-6) were compared using a Students' paired t-test. Levels were significantly elevated before IVIG and normalized to baseline levels after responsive IVIG infusion in all patients enrolled in the study.

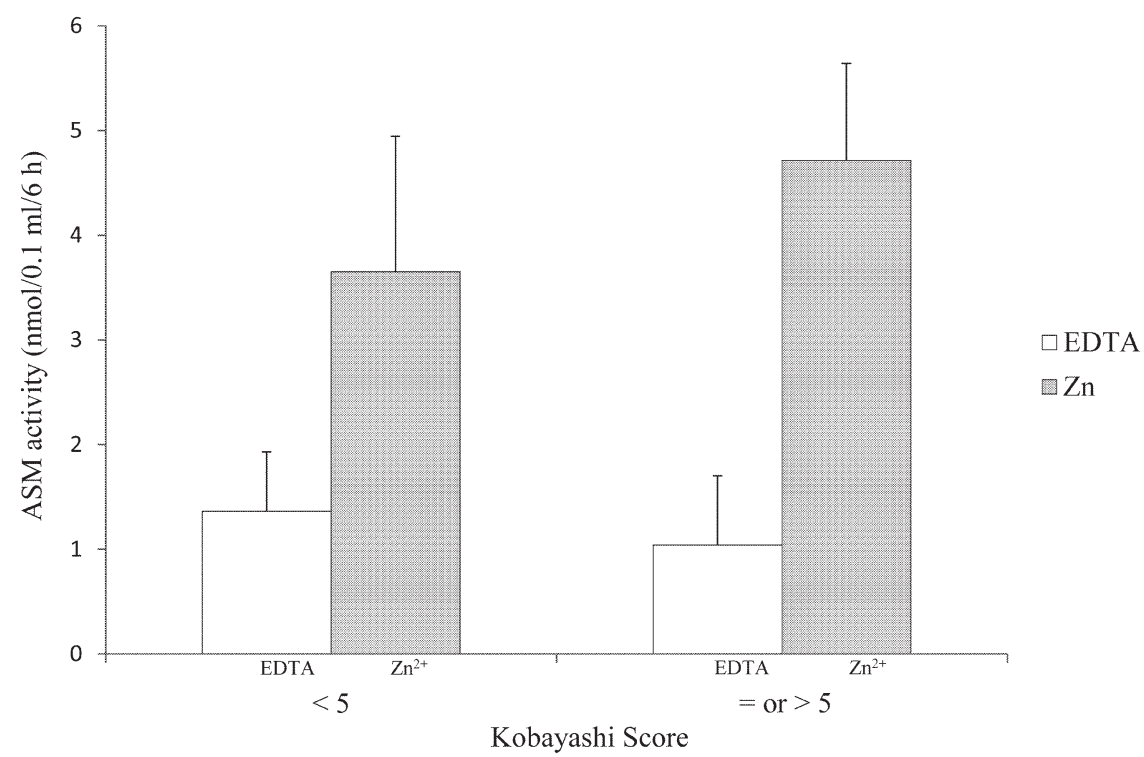

Fig. 3. Serum acid sphingomyelinase (ASM) activity and Kobayashi risk score.

Acid sphingomyelinase (ASM) activity between patients with a Kobayashi risk score $<5$ and those with a risk score $\geq 5$ was compared $(\mathrm{p}>0.05)$.

patients with acute KD. In humans, several forms of sphingomyelinase exist, encoded by independent genes, and with different optimal activities at acidic, neutral, or alkaline $\mathrm{pH}$ levels (Goñi and Alonso 2002). The sphingomyelinase forms identified in this study demonstrated optimum activ- ity at approximately $\mathrm{pH} 5$. These forms were stimulated with the addition of $\mathrm{Zn}^{2+}$ to the assay buffer, thus confirming the authenticity of ASM. The upregulation of ASM as a cellular response, caused by the stimulation of inflammatory cytokines, and elevation of serum S-ASM has been 


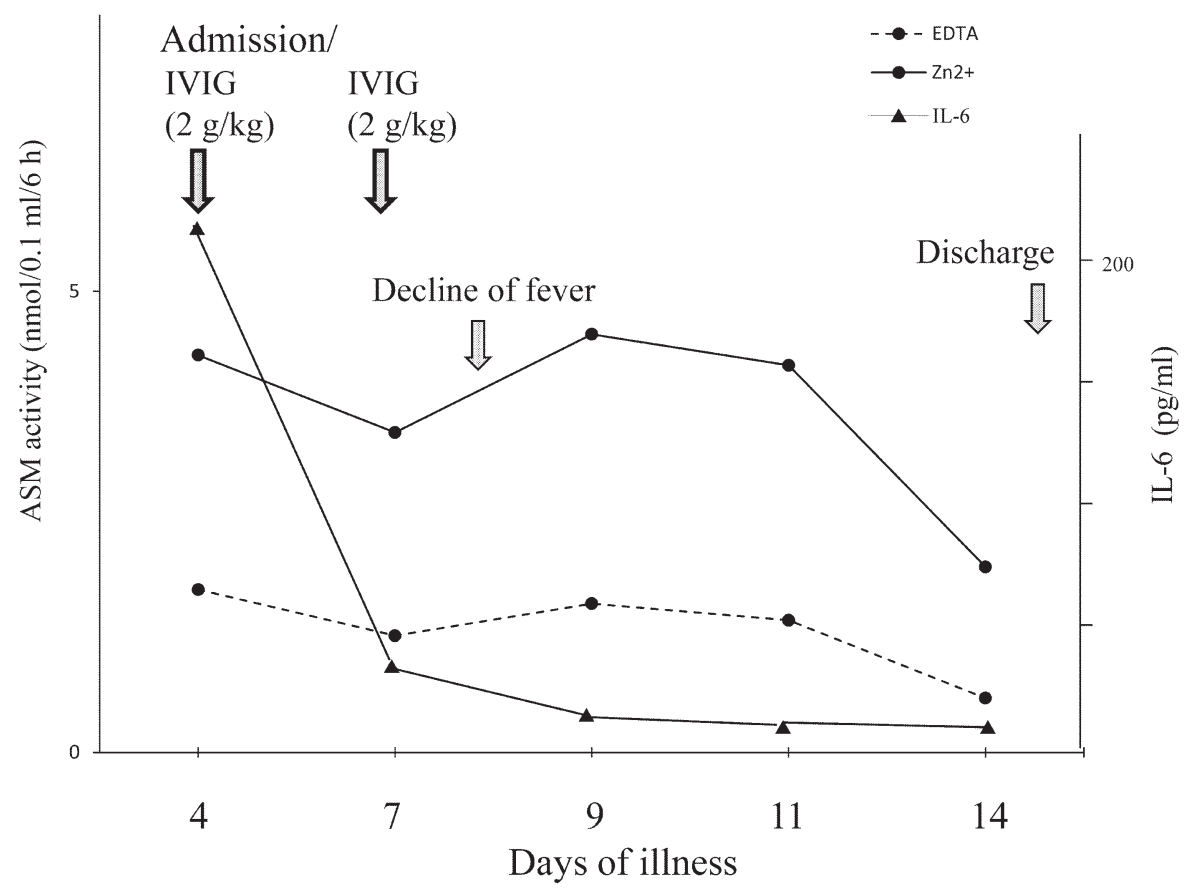

Fig. 4. Clinical course of an acute KD patient resistant to high-dose IVIG.

Shown is the clinical course of an acute KD patient with inflammation resistant to initial infusion of high-dose intravenous immunoglobulin (IVIG). In this case, the patient required second IVIG infusion for resolution of fever. Serum acid sphingomyelinase (ASM) activity and serum interleukin-6 (IL-6) levels were measured on five occasions throughout the clinical course.

Table 3. Correlation Analysis of $\mathrm{Zn}^{2+}$-ASM activity in acute $\mathrm{KD}$ patients.

\begin{tabular}{lcc}
\multicolumn{1}{c}{ Parameter } & $\mathrm{r}$ & $\mathrm{p}$ \\
\hline Serum sodium $(\mathrm{mmol} / \mathrm{L})$ & -1.102 & 0.299 \\
Days of illness & 1.154 & 0.278 \\
AST $(\mathrm{IU} / \mathrm{L})$ & 0.067 & 0.948 \\
Neutrophils $(\%)$ & 2.069 & 0.068 \\
CRP $(\mathrm{mg} / \mathrm{mL})$ & 2.775 & $0.022^{*}$ \\
Platelet count $\left(\times 10^{3} / \mu \mathrm{l}\right)$ & 0.186 & 0.857 \\
Age (months) & 1.286 & 0.230 \\
\hline
\end{tabular}

*p $<0.05$ (Pearson correlation coefficient).

AST, aspartate aminotransferase; CRP, C-reactive protein.

described in several human diseases, including sepsis, heart failure, and diabetes. To the best of our knowledge, this is the first study to report the elevation of serum S-ASM in patients with acute KD. Acute KD affects the vascular endothelial cells through systemic vasculitis; therefore, S-ASM could originate from the vascular lesions, including vascular endothelial cells, which are known to be a rich source of S-ASM.

S-ASM elevation was observed prior to IVIG infusion and this was sustained even after resolution of inflammation. Once serum S-ASM levels were elevated in acute $\mathrm{KD}$, it did appear to take a long time to return to baseline even after resolution of inflammation. This responsiveness differs from that observed in serum IL-6 levels under similar conditions; these were elevated prior to IVIG infusion and quickly returned to normal basal levels after resolution of inflammation. A previous study has described significant S-ASM elevation in patients with hypercytokinemia associated with hemophagocytic lymphohistiocytosis (HLH) (Takahashi et al. 2002). In HLH patients, elevated S-ASM levels reverted to baseline levels after successful treatment and discontinuation of hypercytokinemia. However, a gradual change in S-ASM levels was observed within the different states of inflammation throughout the clinical course. In an HLH patient with hypercytokinemia, elevated levels of serum ferritin - a biomarker for hypercytokinemia in human inflammatory diseases - quickly reverted to baseline levels as a result of treatment with steroids and VP-16, whereas S-ASM serum levels gradually normalized towards baseline levels. The present study showed that ASM is 
involved in the pathophysiology of acute $\mathrm{KD}$ and that serum ASM activity is elevated in patients with acute $\mathrm{KD}$; however, serum ASM may not be an acute biomarker reflective of the state of inflammation in this condition. Studies of various diseases concerning S-ASM all suggested a relative slow decrease in S-ASM activity in response to treatment for diseases in which S-ASM is initially increased (Kornhuber et al. 2015). This effect may be related to the slow turnover, but further investigations are needed to confirm this.

In this study, we investigated the value of serum S-ASM as a biomarker for the prediction of IVIG resistance in acute KD. High-dose IVIG infusion is a standard treatment for this condition and is effective at curbing inflammation in acute KD patients, as well as reducing the incidence of CALs. However, some $10 \%$ of patients have been shown to be nonresponsive to initial high-dose IVIG, and a higher CAL incidence rate is observed in this group. Nonresponsive KD patients are a high-risk group for the development of CALs. Recently, there have been several published reports discussing potential risk scoring systems or biological markers for predicting nonresponsiveness to high-dose IVIG in acute KD patients (Kobayashi et al. 2006; Sleeper et al. 2011; Sato et al. 2013; Wang et al. 2013). Serum S-ASM levels did not show any significant difference between responsive and nonresponsive groups. Furthermore, the Kobayashi score (a widely-used risk scoring system in Japan) revealed no correlation in terms of serum S-ASM between groups with risk score $<5$ and those with risk score $\geq 5$. Thus, serum S-ASM does not appear to be an effective biomarker for predicting IVIG resistance in acute KD. However, a future larger-scale study is recommended in order to clearly delineate the relationship between serum S-ASM and IVIG resistance in cases of acute KD.

In the present study, we have demonstrated that ASM is involved in acute KD. While elevation of serum S-ASM activity is thought to be a consequence of acute KDtriggered inflammation, extracellular secreted ASM may in fact be a contributing factor towards the pathophysiology of acute $\mathrm{KD}$ as well as the post-KD prognosis of complicated coronary arteries.

Sphingolipids, including sphingomyelin and ceramide, have now been recognized as potent bioactive molecules and are implicated in various cellular processes including differentiation, inflammation, and cell death (Maceyka and Spiegel 2014). Ceramide elevation is mediated by the rapid hydrolysis of sphingomyelin by acid or neutral sphingomyelinase and this lipid is catabolized by acid or neutral ceramidase into sphingosine, which can in turn be phosphorylated into phingosine-1-phosphate, thus forming a sphingosine/sphingosin-1-phosphate signaling pathway. These sphingolipid metabolites exist extracellularly and have been shown to be associated with several diseases including atherosclerosis, coronary artery disease, and sepsis (Maceyka and Spiegel 2014). A recent study reported the results of serum analyses of bioactive sphingolipids using tandem sphingolipid metabolomic profiling in patients with hypercytokinemia associated with HLH (Jenkins et al. 2013). In that study, elevated ASM levels with concomitant elevations in sphingosine as well as several ceramides was observed, while levels of sphngosine1-phosphate were significantly decreased. Interestingly, the ratio of $\mathrm{C}_{16}$-ceramide to sphingosine was shown to have prognostic value in cases of HLH. While the present study confirmed the involvement of ASM in acute KD, the significance of ASM upregulation in acute KD should be further investigated and sphingolipid analysis could provide comprehensive information concerning sphingolipids metabolism.

In conclusion, this is the first study to show significant elevation of serum ASM activity in patients with acute KD. Although the clinical significance of elevated serum ASM is not yet clear, future studies may demonstrate the involvement of sphingolipid metabolism in the pathophysiology of KD.

\section{Acknowledgments}

This study was funded in part by grants from the Research on Measures for Intractable Diseases, the Ministry of Health, Labour and Welfare, Japan.

\section{Conflict of Interest}

The authors declare no conflict of interest.

\section{References}

Ayusawa, M., Sonobe, T., Uemura, S., Ogawa, S., Nakamura, Y., Kiyosawa, N., Ishii, M. \& Harada, K. (2005) Revision of diagnostic guidelines for Kawasaki disease (the 5th revised edition). Pediatr. Int., 47, 232-234.

Burns, J.C., Capparelli, E.V., Brown, J.A., Newburger, J.W. \& Glode, M.P. (1998) Intravenous gamma-globulin treatment and retreatment in Kawasaki disease. US/Canadian Kawasaki Syndrome Study Group. Pediatr. Infect. Dis. J., 17, 11441148.

Claus, R.A., Bunck, A.C., Bockmeyer, C.L., Brunkhorst, F.M., Lösche, W., Kinscherf, R. \& Deigner, H.P. (2005) Role of increased sphingomyelinase activity in apoptosis and organ failure of patients with severe sepsis. FASEB J., 19, 17191721.

Doehner, W., Bunck, A.C., Rauchhaus, M., von Haehling, S., Brunkhorst, F.M., Cicoira, M., Tschope, C., Ponikowski, P., Claus, R.A. \& Anker, S.D. (2007) Secretory sphingomyelinase is upregulated in chronic heart failure: a second messenger system of immune activation relates to body composition, muscular functional capacity, and peripheral blood flow. Eur. Heart J., 28, 821-828.

Furusho, K., Nakano, H., Shinomiya, K., Tamura, T., Manabe, Y., Kawarano, M., Baba, K., Kamiya, T., Kiyosawa, N., Hayashidera, T., Hirose, O., Yokoyama, T., Baba, K. \& Mori, C. (1984) High-dose intravenous gammaglobulin for Kawasaki disease. Lancet, 324, 1055-1058.

Goñi, F.M. \& Alonso, A. (2002) Sphingomyelinases: enzymology and membrane activity. FEBS Lett., 531, 38-46.

Górska, M., Barańczuk, E. \& Dobrzyń, A. (2003) Secretory Zn ${ }^{2+}$ dependent sphingomyelinase activity in the serum of patients with type 2 diabetes is elevated. Horm. Metab. Res., 35, 506-507. 
Grammatikos, G., Mühle, C., Ferreiros, N., Schroeter, S., Bogdanou, D., Schwalm, S., Hintereder, G., Kornhuber, J., Zeuzem, S., Sarrazin, C. \& Pfeilschifter, J. (2014) Serum acid sphingomyelinase is upregulated in chronic hepatitis $\mathrm{C}$ infection and non alcoholic fatty liver disease. Biochim. Biophys. Acta, 1841, 1012-1020.

Han, R.K., Silverman, E.D., Newman, A. \& McCrindle, B.W. (2000) Management and outcome of persistent or recurrent fever after initial intravenous gamma globulin therapy in acute Kawasaki disease. Arch. Pediatr. Adolesc. Med., 154, 694-699.

Hui-Yuen, J.S., Duong, T.T. \& Yeung, R.S. (2006) TNF-alpha is necessary for induction of coronary artery inflammation and aneurysm formation in an animal model of Kawasaki disease. J. Immunol., 176, 6294-6301.

Jang, G.C., Kim, H.Y., Ahn, S.Y. \& Kim, D.S. (2003) Raised serum interleukin 15 levels in Kawasaki disease. Ann. Rheum. Dis., 62, 264-266.

Jenkins, R.W., Canals, D., Idkowiak-Baldys, J., Simbari, F., Roddy, P., Perry, D.M., Kitatani, K., Luberto, C. \& Hannun, Y.A. (2010) Regulated secretion of acid sphingomyelinase: implications for selectivity of ceramide formation. J. Biol. Chem., 285, 35706-35718.

Jenkins, R.W., Clarke, C.J., Lucas, J.T. Jr., Shabbir, M., Wu, B.X., Simbari, F., Mueller, J., Hannun, Y.A., Lazarchick, J. \& Shirai, K. (2013) Evaluation of the role of secretory sphingomyelinase and bioactive sphingolipids as biomarkers in hemophagocytic lymphohistiocytosis. Am. J. Hematol., 88, E265E272.

Kobayashi, T., Inoue, Y., Takeuchi, K., Okada, Y., Tamura, K., Tomomasa, T., Kobayashi, T. \& Morikawa, A. (2006) Prediction of intravenous immunoglobulin unresponsiveness in patients with Kawasaki disease. Circulation, 113, 2606-2612.

Kornhuber, J., Rhein, C., Müller, C.P. \& Mühle, C. (2015) Secretory sphingomyelinase in health and disease. Biol. Chem., 396, 707-736.

Maceyka, M. \& Spiegel, S. (2014) Sphingolipid metabolites in inflammatory disease. Nature, 510, 58-67.

Marathe, S., Schissel, S.L., Yellin, M.J., Beatini, N., Mintzer, R., Williams, K.J. \& Tabas, I. (1998) Human vascular endothelial cells are a rich and regulatable source of secretory sphingomyelinase. J. Biol. Chem., 273, 4081-4088.

Newburger, J.W., Takahashi, M., Beiser, A.S., Burns, J.C., Bastian, J., Chung, K.J., Colan, S.D., Duffy, C.E., Fulton, D.R., Glode, M.P., Mason, W.H., Meissner, H.C., Rowley, A.H., Shulman, S.T., Reddy, V., et al. (1991) A single intravenous infusion of gamma globulin as compared with four infusions in the treatment of acute Kawasaki syndrome. N. Engl. J. Med., 324, 1633-1639.

Newburger, J.W., Takahashi, M., Burns, J.C., Beiser, A.S., Chung, K.J., Duffy, C.E., Glode, M.P., Mason, W.H., Reddy, V., Sanders, S.P., Shulman, S.T., Wiggins, J.W., Hicks, R.V., Fulton, D.R., Lewis, A.B., et al. (1986) The treatment of Kawasaki syndrome with intravenous gamma globulin. $N$. Engl. J. Med., 315, 341-347.

Newburger, J.W., Takahashi, M., Gerber, M.A., Gewitz, M.H., Tani, L.Y., Burns, J.C., Shulman, S.T., Bolger, A.F., Ferrieri, P., Baltimore, R.S., Wilson, W.R., Baddour, L.M., Levison, M.E., Pallasch, T.J., Falace, D.A., et al. (2004) Diagnosis, treatment, and long-term management of Kawasaki disease: a statement for health professionals from the Committee on Rheumatic Fever, Endocarditis and Kawasaki Disease, Council on Cardiovascular Disease in the Young, American Heart Association. Circulation, 110, 2747-2771.

Reichel, M., Beck, J., Mühle, C., Rotter, A., Bleich, S., Gulbins, E. \& Kornhuber, J. (2011) Activity of secretory sphingomye- linase is increased in plasma of alcohol-dependent patients. Alcohol. Clin. Exp. Res., 35, 1852-1859.

Research Committee on Kawasaki Disease (1984) Report of subcommittee on standardization of diagnostic criteria and reporting of coronary artery lesions in Kawasaki disease, Ministry of Health and Welfare, Tokyo, Japan (in Japanese).

Sato, S., Kawashima, H., Kashiwagi, Y. \& Hoshika, A. (2013) Inflammatory cytokines as predictors of resistance to intravenous immunoglobulin therapy in Kawasaki disease patients. Int. J. Rheum. Dis., 16, 168-172.

Schissel, S.L., Keesler, G.A., Schuchman, E.H., Williams, K.J. \& Tabas, I. (1998) The cellular trafficking and zinc dependence of secretory and lysosomal sphingomyelinase, two products of the acid sphingomyelinase gene. J. Biol. Chem., 273, 1825018259.

Schissel, S.L., Schuchman, E.H., Williams, K.J. \& Tabas, I. (1996) $\mathrm{Zn}^{2+}$-stimulated sphingomyelinase is secreted by many cell types and is a product of the acid sphingomyelinase gene. $J$. Biol. Chem., 271, 18431-18436.

Schuchman, E.H. (2010) Acid sphingomyelinase, cell membranes and human disease: lessons from Niemann-Pick disease. FEBS Lett., 584, 1895-1900.

Sleeper, L.A., Minich, L.L., McCrindle, B.M., Li, J.S., Mason, W., Colan, S.D., Atz, A.M., Printz, B.F., Baker, A., Vetter, V.L. \& Newburger, J.W. (2011) Evaluation of Kawasaki disease riskscoring systems for intravenous immunoglobulin resistance. $J$. Pediatr., 158, 831-835. e3.

Suzuki, H., Noda, E., Miyawaki, M., Takeuchi, T., Uemura, S. \& Koike, M. (2001) Serum levels of neutrophil activation cytokines in Kawasaki disease. Pediatr. Int., 43, 115-119.

Takahashi, T., Abe, T., Sato, T., Miura, K., Takahashi, I., Yano, M., Watanabe, A., Imashuku, S. \& Takada, G. (2002) Elevated sphingomyelinase and hypercytokinemia in hemophagocytic lymphohistiocytosis. J. Pediatr. Hematol. Oncol., 24, 401-404.

Tremoulet, A.H., Best, B.M., Song, S., Wang, S., Corinaldesi, E., Eichenfield, J.R., Martin, D.D., Newburger, J.W. \& Burns, J.C. (2008) Resistance to intravenous immunoglobulin in children with Kawasaki disease. J. Pediatr., 153, 117-121.

Uehara, R., Belay, E.D., Maddox, R.A., Holman, R.C., Nakamura, Y., Yashiro, M., Oki, I., Ogino, H., Schonberger, L.B. \& Yanagawa, H. (2008) Analysis of potential risk factors associated with nonresponse to initial intravenous immunoglobulin treatment among Kawasaki disease patients in Japan. Pediatr. Infect. Dis. J., 27, 155-160.

Wang, Y., Wang, W., Gong, F., Fu, S., Zhang, Q., Hu, J., Qi, Y., Xie, C. \& Zhang, Y. (2013) Evaluation of intravenous immunoglobulin resistance and coronary artery lesions in relation to Th1/Th2 cytokine profiles in patients with Kawasaki disease. Arthritis Rheum., 65, 805-814.

Weng, K.P., Hsieh, K.S., Huang, S.H., Ou, S.F., Lai, T.J., Tang, C.W., Lin, C.C., Ho, T.Y., Liou, H.H. \& Ger, L.P. (2013) Interleukin-18 and coronary artery lesions in patients with Kawasaki disease. J. Chin. Med. Assoc., 76, 438-445.

Wong, M.L., Xie, B., Beatini, N., Phu, P., Marathe, S., Johns, A., Gold, P.W., Hirsch, E., Williams, K.J., Licinio, J. \& Tabas, I. (2000) Acute systemic inflammation up-regulates secretory sphingomyelinase in vivo: a possible link between inflammatory cytokines and atherogenesis. Proc. Natl. Acad. Sci. USA, 97, 8681-8686.

Wu, J.M., Chiou, Y.Y., Hung, W.P., Chiu, N.T., Chen, M.J. \& Wang, J.N. (2011) Urinary cytokines and renal Doppler study in Kawasaki disease. J. Pediatr., 156, 792-797.

Zeidan, Y.H. \& Hannun, Y.A. (2010) The acid sphingomyelinase/ ceramide pathway: biomedical significance and mechanisms of regulation. Curr. Mol. Med., 10, 454-466. 